\title{
Applying a Taguchi-based fuzzy logic approach to optimize hydrothermal pretreatment of canola seeds using multi-response performance index
}

\author{
Ramiro J. Sánchez ${ }^{1, *}$, María J. Blas ${ }^{1}$, María B. Fernández ${ }^{2,3}$ and Susana M. Nolasco ${ }^{2,4}$ \\ 1 INGAR, UTN-CONICET, Santa Fe, Argentina \\ ${ }^{2}$ Núcleo TECSE, Facultad de Ingeniería, Universidad Nacional del Centro de la Provincia de Buenos Aires, Olavarría, Argentina \\ ${ }^{3}$ CIFICEN, Universidad Nacional del Centro de la Provincia de Buenos Aires - CONICET-CIC, Tandil, Argentina \\ ${ }^{4}$ CIC, Comisión de Investigaciones Científicas de la Provincia de Buenos Aires, La Plata, Argentina
}

Received 28 July 2020 - Accepted 27 December 2020

\begin{abstract}
The Taguchi method with fuzzy logic was applied for optimizing the hydrothermal pretreatment of canola with multiple performance responses (oil extraction yield, free acidity and peroxide index) using published data. The canola seeds had been subjected to hydrothermal pretreatments using steam in an autoclave whose base was perforated, under different conditions of temperature $(100,120$ and $\left.130^{\circ} \mathrm{C}\right)$, time $(5,15$ and $30 \mathrm{~min})$ and granulometry (entire, broken and ground seeds), and the responses were measured as performance characteristics of the process. The output value that represents the responses was called multi-response performance index (MRPI), and the significance of the experimental factors was analyzed by ANOVA. A confirmation test of the optimum parameters was carried out to verify the optimum parameters, obtaining a predicted MRPI of 0.588 , while the experimental value was of 0.849 , and the MRPI calculated using the predicted values from the literature was of 0.577 .
\end{abstract}

Keywords: canola seeds / processing / Taguchi / fuzzy logic

\begin{abstract}
Résumé - Application d'une approche de logique floue de type Taguchi pour optimiser le prétraitement hydrothermique des graines de canola en utilisant l'indice de performance multiréponse. La méthode de Taguchi à logique floue a été appliquée pour optimiser le prétraitement hydrothermique du canola prenant en compte de multiples réponses de performance (rendement d'extraction de l'huile, acidité libre et indice de peroxyde) en utilisant des données publiées. Les graines de canola ont été soumises à des prétraitements hydrothermiques à la vapeur dans un autoclave dont la base était perforée, sous différentes conditions de température $\left(100,120\right.$ et $\left.130^{\circ} \mathrm{C}\right)$, de durée $(5,15$ et $30 \mathrm{~min})$ et de granulométrie (graines entières, brisées et broyées), et les réponses ont été mesurées en tant que caractéristiques de performance du procédé. La valeur de sortie qui représente les réponses a été appelée indice de performance multi-réponse (MRPI), et l'importance des facteurs expérimentaux a été analysée par ANOVA (analyse de variance). Un test de confirmation des paramètres optimaux a été effectué pour vérifier les paramètres optimaux, obtenant un MRPI prédit de 0,588 , alors que la valeur expérimentale était de 0,849 ; le MRPI calculé en utilisant les valeurs prédites de la littérature était de 0,577.
\end{abstract}

Mots clés : graine de canola / traitement / Taguchi / logique floue

\section{Introduction}

Canola oil, widely consumed, has a high content of unsaturated fatty acids and vitamin E (780.2 ppm, Sánchez et al., 2018a). In recent years, emerging technologies for the

*Correspondence: $r$ sanchez@santafe-conicet.gov.ar extraction of this oil have been studied, such as the application of ultrasound, microwaves and the use of ethanol as a solvent, among others (Carré et al., 2018; Sánchez et al., 2019a, 2019b; Mohseni et al., 2020). The Taguchi method uses a special experimental design called orthogonal array to study the entire parameter space with a small number of experiments. This method has been widely used to improve the manufacturing processes of high-precision mechanical parts, and in recent 
years, it has been applied to study processes involving biological matrices, such as foods (Azin et al., 2007; Rao et al., 2008; Fernández et al., 2014). Traditionally the Taguchi method has been used for the optimization of a single performance characteristic, and in several works, it has applied to study oil extraction processes. Fernández et al. (2014) used the method to optimize the hydrothermal pretreatment of canola seeds, analyzing yield and quality responses individually, and selecting one of the responses for calculating the optimal parameters. Rombaut et al. (2015) studied the influence of different operating conditions on grape seed oil extraction by cold pressing using Taguchi methodology. Similarly to the case cited above, they optimized oil and polyphenol extraction yields as individual responses. Morakinyo and Bamgboye (2017) used Taguchi's methodology to optimize the sterilization of palm oil from a novel vertical sterilizer on a pilot scale, and response surface methodology for the optimization of the experimental design. Artificial Intelligence were begun to study for the prediction and modeling of food processes. Sánchez et al. (2018b) applied an artificial neural network to model the yields of canola oil extraction with different pretreatments. In this context, fuzzy logic is a mathematical theory of inexact reasoning that allows modeling the human reasoning process in linguistic terms (Ross, 2016). It is a form of many-valued logic that deals with fluid or approximate reason rather than precise or exact statements. In contrast to "crisp logic", where binary sets are "true or false", the truth values of fuzzy logic variables range between 0 and 1. Fuzzy logic has also been used to handle the concept of partial truth by Kulekci et al. (2016), where the truth value may range between completely true and completely false.

The optimization of multiple performance characteristics of a process can be transformed into the optimization of a single performance index through fuzzy logic. Thus, the integration of fuzzy logic with the Taguchi method can be used to solve the optimization of multiple performance characteristics. This approach has been applied by several authors to improve the characteristics of welding processes and the milling of machine parts Tarng et al. (2000); Mahesh and Rajesh (2014); Kulekci et al. (2016). However, it has not yet been studied for technological processes that involve biological matrices such as oilseeds.

The purpose of this paper was to evaluate the use of fuzzy logic and the Taguchi method for the optimization of the hydrothermal pretreatment of canola seeds with multiple performance characteristics (oil extraction yield and quality indices). This work describes the application of the fuzzy logic analysis combined with the Taguchi method to optimize multiple performance characteristics that were previously subjected to a decision-making process. In this sense, the novel contribution of this work is the application of this technique to the hydrothermal pretreatment and extraction of canola oil, allowing to evaluate different and complex responses such as oil yield and quality index and facilitating its industrial application.

\section{Materials and methods}

Data reported by Fernández et al. (2014) who worked with the experimental design presented in Table $1\left(\mathrm{~L}_{9}\right.$ orthogonal array), were used in the present study (Tab. 1).
Table 1. L orthogonal design.

\begin{tabular}{llll}
\hline$[1,0]$ Experiment & $\begin{array}{lll}{[0,2-4] \text { Levels }} \\
\text { B }\end{array}$ & C & D \\
\hline E1 & 1 & 1 & 1 \\
E2 & 2 & 2 & 2 \\
E3 & 3 & 3 & 3 \\
E4 & 1 & 1 & 3 \\
E5 & 2 & 2 & 1 \\
E6 & 3 & 3 & 2 \\
E7 & 1 & 1 & 2 \\
E8 & 2 & 2 & 3 \\
E9 & 3 & 3 & 1 \\
\hline
\end{tabular}

Table 2. Experimental factors and levels.

\begin{tabular}{lllll}
\hline Factor & Parameter & Level 1 & Level 2 & Level 3 \\
\hline B & Temperature $\left({ }^{\circ} \mathrm{C}\right)$ & 100 & 120 & 130 \\
C & Time (min) & 5 & 15 & 30 \\
D & Granulometry & Ground & Broken & Entire \\
& & seeds & seeds & seeds \\
\hline
\end{tabular}

Samples of canola seeds of the Barrel variety were subjected to hydrothermal pretreatments using steam in an autoclave whose base was perforated, under the conditions of temperature, time and granulometry presented in Table 2 . The responses were measured as performance characteristics for oil yield ratio (ratio of the oil yield of pretreated samples to that of untreated samples), acidity value (AV) and peroxide index (PV). (Tab. 2).

\subsection{Signal-to-noise ratio}

The Taguchi method uses the signal-to-noise ratio $(\mathrm{SN})$ to analyze the sources of variation, representing a relationship or comparison between the desirable value (mean) for the output characteristic and the "noise" or the undesirable value for the output characteristic. The $\mathrm{SN}$ ratio, often expressed in decibels, is a measure of the variation between experiments when noise factors are present (Zhou et al., 2010).

In order to maximize the oil yield ratio, the $\mathrm{SN}$ value was obtained by equation (1):

$$
S N=-10 \cdot \log \left[\frac{\sum_{k=1}^{n} 1 / x_{k}^{2}}{n}\right] .
$$

In the case of the quality indices (AV and PV), where minimum values are desired, the $\mathrm{SN}$ ratio was calculated using equation (2):

$$
S N=-10 \cdot \log \left[\frac{\sum_{k=1}^{n} x_{k}^{2}}{n}\right],
$$


(A)

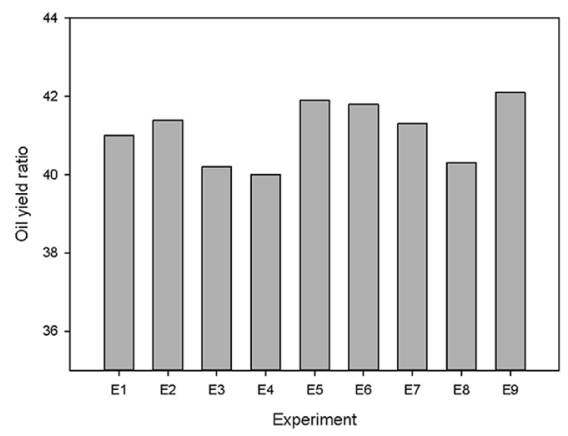

(B)

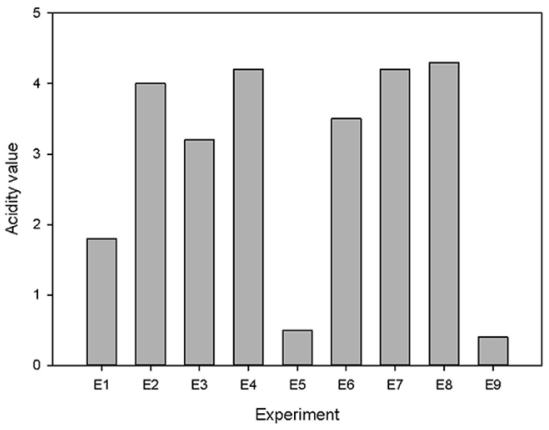

(C)

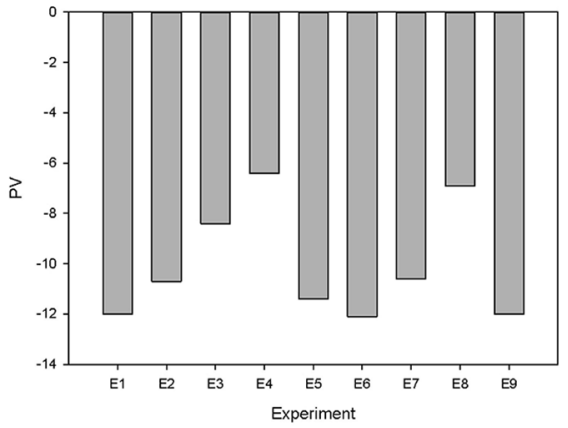

Fig. 1. Signal-to-noise ratios for the responses: (A) oil yield, (B) acidity, and (C) peroxide index.

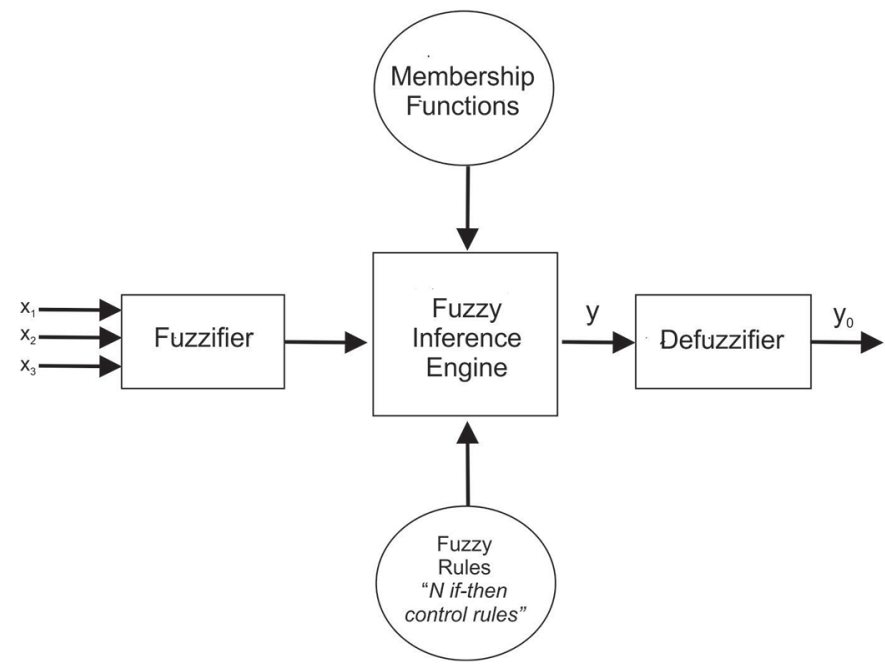

Fig. 2. Structure of the fuzzy logic unit. $X_{1}: S / N$ ratio for the oil yield, $\mathrm{x}_{2}: \mathrm{S} / \mathrm{N}$ ratio for the acidity value $(\mathrm{AV}), \mathrm{x}_{3}: \mathrm{S} / \mathrm{N}$ ratio for the peroxide index (PV), and y: multi-response performance index (MRPI).

where $x_{k}$ is the response obtained experimentally, $\mathrm{n}$ is the number of experiments, and $\mathrm{k}$ is the number of repetitions. Figure 1 presents the SN values calculated by Fernández et al. (2014) for the studied responses (Fig. 1):

\subsection{Fuzzy logic analysis}

The multiple performance characteristics were obtained using the fuzzy logic analysis. A fuzzy logic unit consists of a fuzzifier, a fuzzy knowledge base, an inference engine and a defuzzifier. First, the fuzzifier converts the $\mathrm{SN}$ values into fuzzy inputs using membership functions. Then the inference engine applies compositional rules of inference using the implications of the knowledge base to generate fuzzy outputs. Finally, the defuzzifier converts the fuzzy values into a crisp output (Tzeng and Chen, 2007). The final structure of the fuzzy unit was the one presented in Figure 2.

In our case, the fuzzy logic unit took 3 inputs $\left(\mathrm{x}_{1}, \mathrm{x}_{2}\right.$ and $\left.\mathrm{x}_{3}\right)$ and produced 1 output $\left(\mathrm{y}_{0}\right)$. Each input refers to $\mathrm{SN}$ for oil yield ratio, acidity value and peroxide value, respectively. The output y is called multi-response performance index (MRPI) (Tarng et al., 2000; Tzeng and Chen, 2007; Mahesh and Rajesh, 2014).

The knowledge base consisted of 27 rules designed as "ifthen" instructions. Such rules evaluate the values of the inputs over the fuzzy subsets to provide a suitable output. Each fuzzy subset was defined by the corresponding membership function $(\mu)$.

In this work, 3 fuzzy subsets $E i, F i$ and $G i$ were assigned for each input $i$ (Figs. 3-5). For example, in the case of $\mathrm{x}$, the fuzzy subsets were defined as follows:

The fuzzy logic unit used 7 fuzzy subsets assigned to the output y (Fig. 6). In this case, each subset depicts the degrees of membership of the MRPI value to a subset $H$ designed according the following categories: extremely low (EL), very low (VL), low (L), medium (M), high (H), very high (VH) and extremely high $(\mathrm{EH})$.

Thus 27 fuzzy rules were designed considering that the performance characteristics increase with increasing $\mathrm{SN}$ ratios. The basic structure of these rules is an "if-then" definition that uses the 3 inputs and a single output as follows:

Rule \#number: If $\mathrm{x}_{1}$ is $E 1, \mathrm{x}_{2}$ is $F 2$ and $\mathrm{x}_{3}$ is $G 3$ then $\mathrm{y}$ is $H$

where $E, F, G$ and $H$ are fuzzy subsets defined over each variable by the corresponding membership functions (e.g. $\mu E 1, \mu F 2, \mu G 3$ and $\mu H)$.

Table 3 presents the full set of rules applied in the present work. For example, rule number 6 specifies that if Yield is Low (L), AV is Medium (M) and PV is High (H) then MRPI is Medium (M). It is important to point out that the set of fuzzy rules was applied following a switch composition (cascade operation). That is, if rule number $\mathrm{N}$ is not satisfiable, then rule number $\mathrm{N}+1$ will be tested.

The fuzzy reasoning of the output obtained from these rules generates a fuzzy output. The membership function of the fuzzy output was designed adopting the "max-min" compositional operation over the membership functions detailed per each input. That is:

$$
\begin{aligned}
\mu_{H_{0}}(y)= & \left(\mu_{E_{1}}\left(x_{1}\right) \wedge \mu_{F_{1}}\left(x_{2}\right) \wedge \mu_{G_{1}}\left(x_{3}\right) \wedge \mu_{H_{1}}(y)\right) \vee \ldots \\
& \left(\mu_{E_{n}}\left(x_{1}\right) \wedge \mu_{F_{n}}\left(x_{2}\right) \wedge \mu_{G_{n}}\left(x_{3}\right) \wedge \mu_{H_{n}}(y)\right),
\end{aligned}
$$

where $\wedge$ is the "minimum" operation, and $\vee$ is the "maximum" operation (Tarng et al., 2000). 


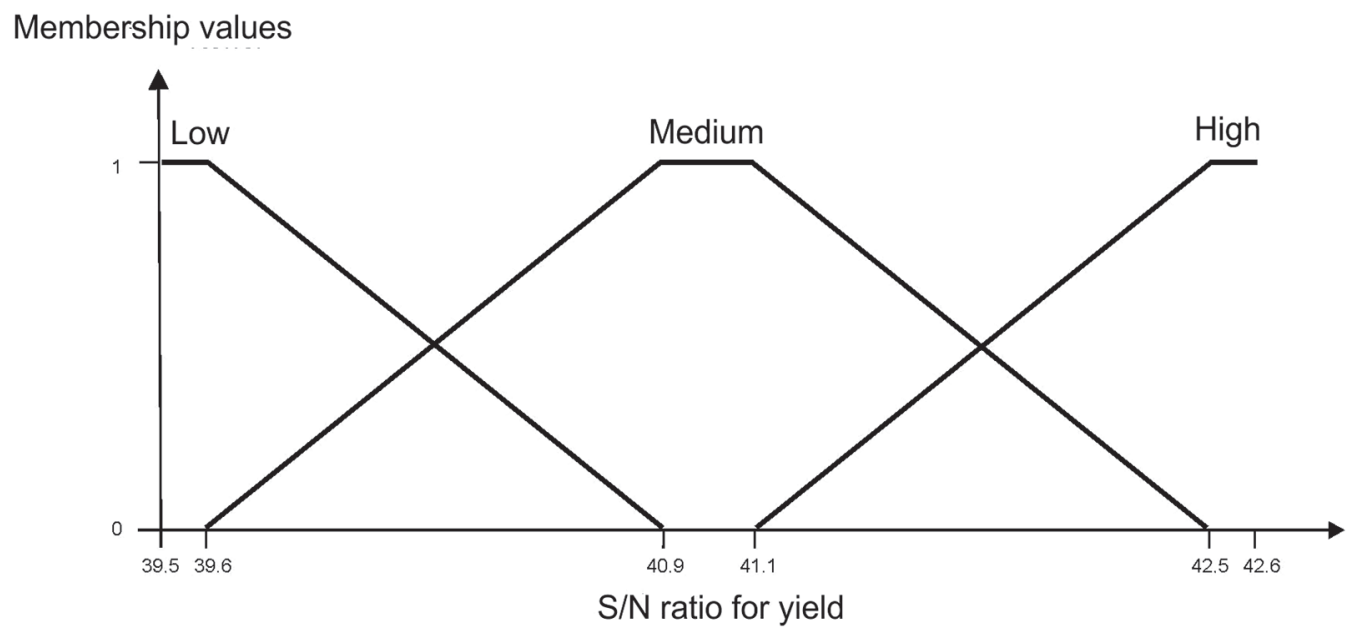

Fig. 3. Membership functions for oil yield.

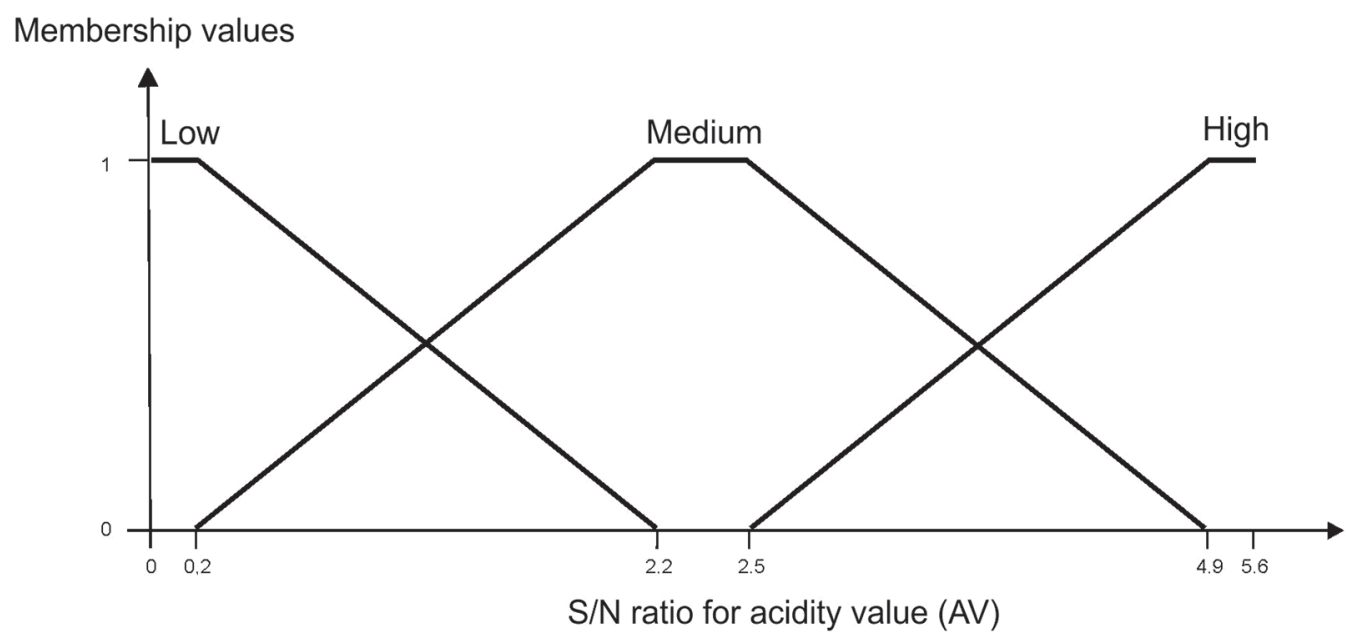

Fig. 4. Membership functions for acidity value (AV).

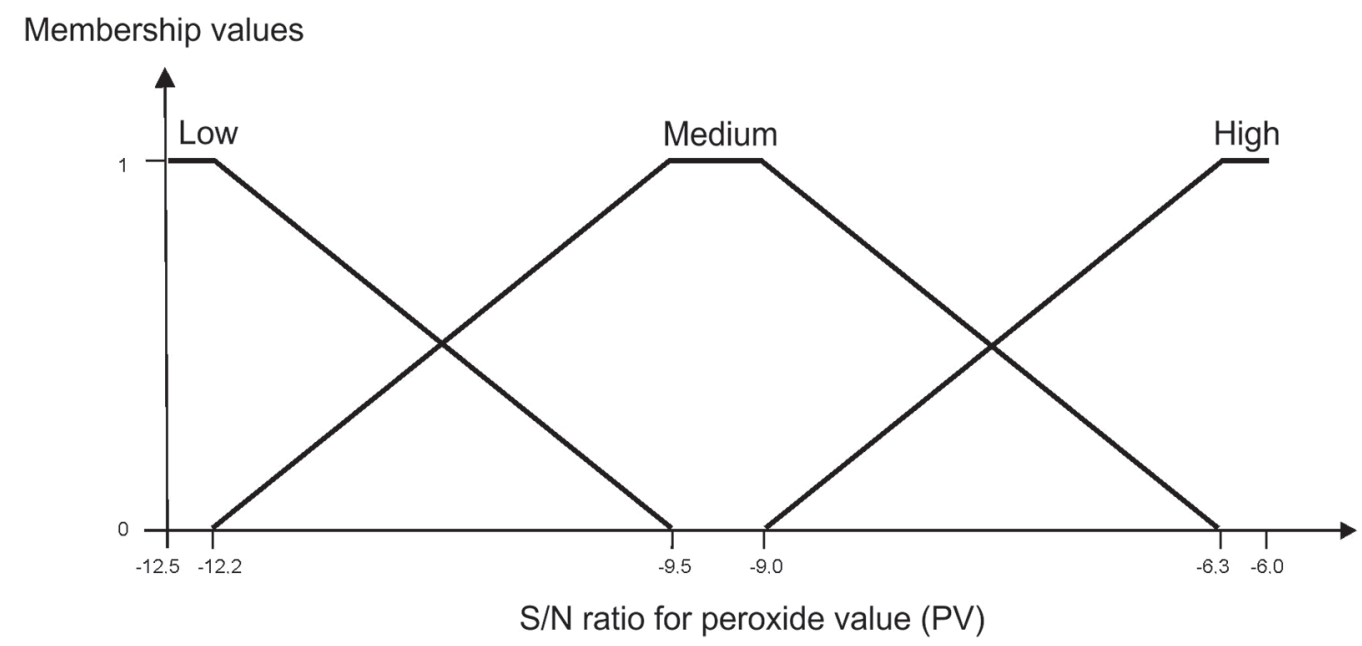

Fig. 5. Membership functions for peroxide index (PV). 
Membership values

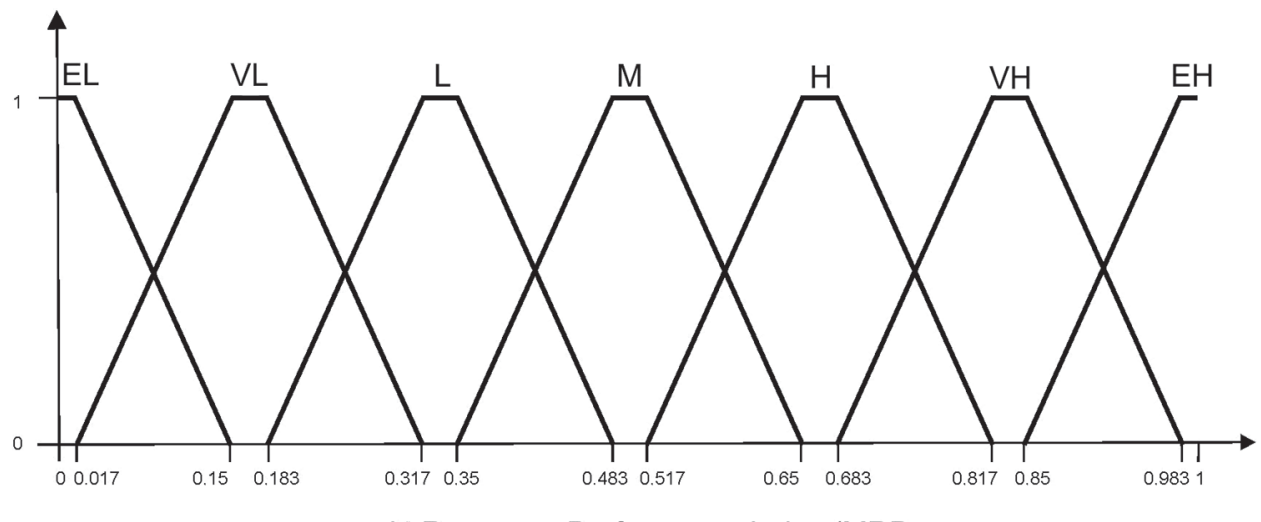

Iviuïl-Response Performance Index (MRPI)

Fig. 6. Membership functions for the multi-response performance index (MRPI).

Table 3. Table of fuzzy rules.

\begin{tabular}{|c|c|c|c|c|}
\hline Rule & Yield & AV & PV & MRPI \\
\hline 2 & Low & Low & Medium & VL \\
\hline 4 & Low & Medium & Low & VL \\
\hline 5 & Low & Medium & Medium & $\mathrm{L}$ \\
\hline 6 & Low & Medium & High & M \\
\hline 9 & Low & High & High & $\mathrm{H}$ \\
\hline 10 & Medium & Low & Low & VL \\
\hline 11 & Medium & Low & Medium & $\mathrm{L}$ \\
\hline 12 & Medium & Low & High & M \\
\hline 13 & Medium & Medium & Low & $\mathrm{L}$ \\
\hline 18 & Medium & High & High & $\mathrm{VH}$ \\
\hline 19 & High & Low & Low & $\mathrm{L}$ \\
\hline 20 & High & Low & Medium & M \\
\hline 21 & High & Low & High & $\mathrm{H}$ \\
\hline 22 & High & Medium & Low & M \\
\hline 23 & High & Medium & Medium & $\mathrm{H}$ \\
\hline 24 & High & Medium & High & $\mathrm{VH}$ \\
\hline 25 & High & High & Low & $\mathrm{H}$ \\
\hline 26 & High & High & Medium & VH \\
\hline 27 & High & High & High & $\mathrm{EH}$ \\
\hline
\end{tabular}

EL: extremely low; VL: very low; L: Low; M: medium; H: high; VH: very high; EH: extremely high.

Finally, the center of gravity method was adopted as the defuzzification method to transform the fuzzy output $\mu_{H_{0}}(y)$ into a crisp value $y_{0}$, given by equation (4):

$$
y_{0}=\frac{\sum y \mu_{H_{0}}(y)}{\sum \mu_{H_{0}}(y)} .
$$

The software MATLAB was used for all the calculations.

\section{Results and discussion}

\subsection{Multi-response performance index}

Table 4 presents the experimental results for MRPI obtained using the experimental design described above.

Assuming the no interaction model proposed by Taguchi, the mean responses for each level were calculated (Fernández 
Table 4. Multi-response performance index (MRPI) obtained for each experiment.

\begin{tabular}{ll}
\hline Experiment & MRPI \\
\hline E1 & 0.316 \\
E2 & 0.578 \\
E3 & 0.434 \\
E4 & 0.642 \\
E5 & 0.360 \\
E6 & 0.512 \\
E7 & 0.585 \\
E8 & 0.611 \\
E9 & 0.340 \\
\hline
\end{tabular}

Table 5. Mean responses for each level of the parameters for the analysis of the MRPI.

\begin{tabular}{|c|c|c|c|}
\hline \multirow[b]{2}{*}{ Control factor } & \multicolumn{3}{|c|}{ [0,2-4]Mean MRPI } \\
\hline & Level 1 & Level 2 & Level 3 \\
\hline B & 0.514 & 0.516 & 0.429 \\
\hline $\mathrm{C}$ & 0.480 & 0.520 & 0.460 \\
\hline $\mathrm{D}$ & 0.339 & 0.558 & 0.562 \\
\hline
\end{tabular}

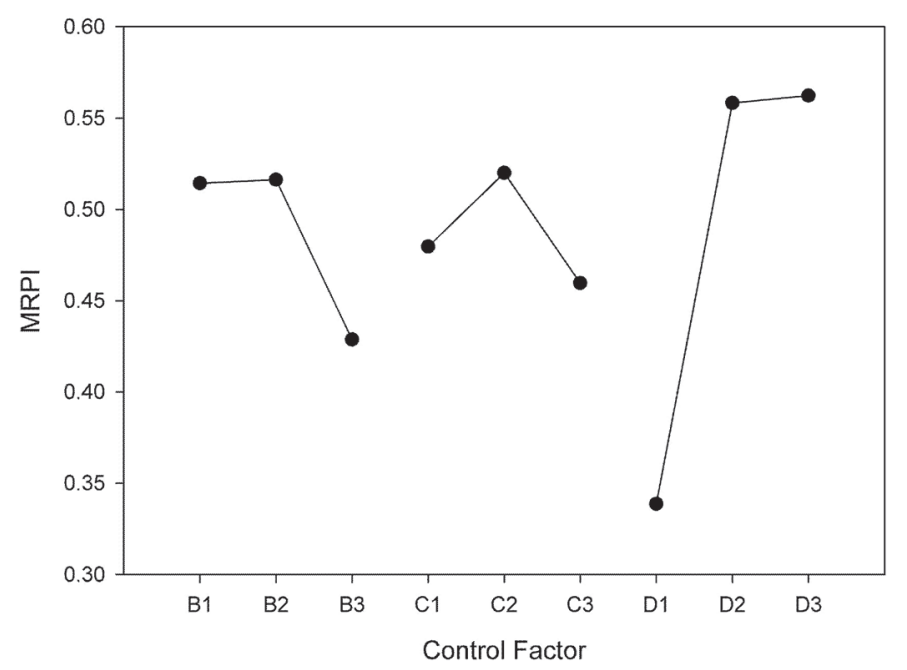

Fig. 7. Effect of the control factors on the multi-response performance index (MRPI).

et al., 2014), in this case for the MRPI, which are presented in Table 5 and graphically in Figure 7.

The highest MRPI value corresponds to the lowest variance of the responses around the desired values. However, it is necessary to evaluate the relative effect of the analyzed parameters on the studied responses in order to determine the optimal conditions more accurately.

\subsection{Analysis of variance}

ANOVA was used to study the significance of the experimental factors (Fernández et al., 2014). The ANOVA results are shown in Table 6.

The results of the analysis of variance showed a larger contribution of parameters B (temperature) and D (granulometry) on the process, with the latter being the most important, whereas the contribution of parameter $\mathrm{C}$ (time), due its low value, was treated as error using the pooling technique (Özdemir et al., 2004; Fernández et al., 2014) These results are in agreement with those obtained by analyzing the responses of yield, acidity and peroxide index individually (Fernández et al., 2014).

The analysis of Figure 7 and Table 6 shows that in the case of temperature (B), the levels 1 and $2\left(100\right.$ and $120^{\circ} \mathrm{C}$, respectively) are the levels with the highest MRPI value. A large contribution of granulometry (D) can also be observed, with levels 2 and 3 (broken and entire seeds, respectively) having the highest MRPI. When these values are compared to the results obtained for each response individually, the influence of the 3 responses on the MRPI values can be observed. For example, in the case of factor D, the oil yield obtained at level 2 was significantly higher than that obtained at level 3, but the quality indices showed the opposite behaviour, whereas MRPI maintained a constant value for these levels, showing a compensation of the effect of the responses.

Taking the above into account, it was possible to determine the following optimum parameters: temperature 100 and $120^{\circ} \mathrm{C}$ (levels 1 and 2 of factor B), 5 minute pretreatments, corresponding to the lowest level of factor $\mathrm{C}$ (since the contribution of this factor was attributed to error), and broken and entire seeds (levels 2 and 3 of factor D). In order to evaluate and compare the obtained results with the experimental values and the predicted values reported in the literature, a temperature of $120^{\circ} \mathrm{C}, 5$ minutes and broken seeds were selected, which are the same conditions selected by Fernández et al. (2014).

\subsection{Confirmation test}

The predicted response for the additional experiment proposed by Fernández et al. (2014) for the optimum factor levels is calculated by equation (5):

$$
\begin{aligned}
S N p r & =S N+(M B 2-S N)+(M C 1-S N) \\
& +(M D 2-S N)+\text { error }
\end{aligned}
$$

where $S N$ is the mean response of all the proposed experiments for the experimental design, and MB2, MC1 and MD2 correspond to the selected levels of factor B, C and D, respectively. Since the contribution of factor $\mathrm{C}$ can be treated as error due to its low mean square value in ANOVA (calculated as the ratio of the sum of square value to the degrees of freedom, Table 6), the terms of this factor can be simplified. The predicted MRPI value calculated by equation (5), the MRPI corresponding to the values predicted by Fernández et al. (2014) and the experimental MRPI are presented in Table 7. Since no experimental PV value was 
Table 6. Analysis of Variance (ANOVA).

\begin{tabular}{llllll}
\hline Sources of variation & Sum of squares & Degrees of freedom & Mean square & Pure sum of squares & Percentage contribution (\%) \\
\hline B & 0.02 & 2 & 0.01 & 0.02 & 15.38 \\
C & 0.01 & 2 & - & - & - \\
D & 0.1 & 2 & 0.05 & 0.1 & 76.92 \\
Error & 0.01 & 2 & - & - & - \\
"Pooled" error & 0.02 & 4 & 0.005 & 0.01 & 7.69 \\
Total variation & 0.13 & 8 & - & - & 100.00 \\
\hline
\end{tabular}

Table 7. Comparison between the predicted and experimental MRPI values.

\begin{tabular}{llcc}
\hline & & {$[0,2-4]$ Optimum parameters } \\
& Predicted & Predicted values* & Experimental \\
\hline Level & B2C1D2 & B2C1D2 & $1 \mathrm{D} 2$ \\
Oil yield (\%) & - & 120.2 & $120.2 \pm 2.0$ \\
Acidity value (\% oleic) & - & 0.62 & $0.68 \pm 0.06$ \\
Peroxide index & - & 3.7 & ND \\
MRPI & 0.588 & 0.577 & 0.842 \\
\hline
\end{tabular}

*Fernández et al., 2014

ND: not detected

detected for E10, the PV value predicted by the Fernández et al. (2014) model was adopted for the calculation of MRPI.

The predicted MRPI value obtained by applying fuzzy logic to the Taguchi method was similar to that obtained by Fernández et al. (2014), indicating the correlation of the proposed approach with the conventional Taguchi method. It is worth noting that using a multi-response index allows to explore all the studied responses (yield, acidity value and peroxide index) to obtain the optimum parameters, thus representing an improvement over the traditional method, by which the optimum parameters are obtained by considering a single response.

\section{Conclusions}

In this paper, the use of Taguchi-based fuzzy logic for the optimization of the hydrothermal pretreatment of canola seeds allowed to successfully analyze yield and quality responses simultaneously by means of a multi-response performance index (MRPI). The predicted MRPI values were compared to experimental MRPI values and to predicted values reported in the literature, observing an agreement between the results. However, the use of MRPI from the application of the fuzzy logic tool allowed to take into account all the studied responses to obtain the optimal conditions, in contrast to other works where from different responses it was necessary to select the main one for the decision making. The approach proposed in this work is an efficient method for the optimization of manufacturing systems by considering multiple performance characteristics of both process and product. Its application in industrial processes with multiple objectives is promising.

\section{Nomenclature}

$\mathrm{E}$

AV

PV

$\mathrm{SN}$

$\mathrm{x}_{\mathrm{i}}$

$\mathrm{y}_{\mathrm{i}}$

$\mathrm{E}_{\mathrm{i}}, \mathrm{F}_{\mathrm{i}}, \mathrm{G}_{\mathrm{i}}, \mathrm{H}_{\mathrm{i}}$

$\mu_{\mathrm{ji}}$

$\wedge$

V

EL

VL

$\mathrm{L}$

$\mathrm{M}$

$\mathrm{H}$

$\mathrm{VH}$

$\mathrm{EH}$

MRPI

MB2, MC1, MD2

\section{Subscripts}

i: $0,1,2, \ldots, n$ series terms

j: E, F, G, H.
Experiment

Acidity value

Peroxide index

Signal-to-noise ratio

Input of fuzzy engine

Output of fuzzy engine

Fuzzy subsets

Membership function

Minimum operation

Maximum operation

Fuzzy rule. Extremely low

Fuzzy rule. Very low

Fuzzy rule. Low

Fuzzy rule. Medium

Fuzzy rule. High

Fuzzy rule. Very high

Fuzzy rule. Extremely high

Multi-response performance index

Selected levels of factor B, C and D, respectively 


\section{Conflict of interest}

The authors declare no conflict of interests.

Acknowledgments. The authors acknowledge the financial support from ANPCyT (Agencia Nacional de Promoción Científica y Tecnologica) (Grant Number: PICT 2012-1442) and Facultad de Ingeniería, Universidad Nacional del Centro de la Provincia de Buenos Aires, Argentina (Grant Number: 03-E170).

\section{References}

Azin M, Moravej R, Zareh D. 2007. Production of xylanase by Trichoderma longibrachiatum on a mixture of wheat bran and wheat straw: optimization of culture condition by Taguchi method. Enzyme Microb Tech 40(4): 801-5.

Carré P, Citeau M, Dauguet S. 2018. Hot ethanol extraction: economic feasibility of a new and green process. OCL 25(2): D206.

Fernández MB, Burnet MA, Perez EE, Crapiste GH, Nolasco SM. 2014. Taguchi's methodology for determining optimum operating conditions in hydrothermal pretreatments applied to canola seeds. Can J Chem Eng 92(7): 1239-46.

Kulekci MK, Esme U, Ocalir S, Ustun D, Kazancoglu Y. 2016. Tensile shear strength and elongation of FSW parts predicted by Taguchi-based fuzzy logic. Mater Test 58(4): 351-6.

Mahesh TP, Rajesh R. 2014. Optimal selection of process parameters in $\mathrm{CNC}$ end milling of Al 7075-T6 aluminium alloy using a Taguchi-fuzzy approach. Proc Mat Sci 5: 2493-502.

Mohseni NM, Mirzaei HO, Moghimi M. 2020. Optimization of producing oil and meal from canola seeds using microwavepulsed electric field pretreatment. OCL 27: 2.

Morakinyo TA, Bamgboye AI. 2017. Optimization of operation parameters of a vertical sterilizer of medium-scale oil palm mill using Taguchi method. J Food Proc Eng 40(3): e12453.
Özdemir C, Akın AN, Yıldırım R. 2004. Low temperature CO oxidation in hydrogen rich streams on Pt-SnO 2/A1 2 O 3 catalyst using Taguchi method. Appl Catal A-Gen 258(2): 145-52.

Rao RS, Kumar CG, Prakasham RS, Hobbs PJ. 2008. The Taguchi methodology as a statistical tool for biotechnological applications: a critical appraisal. Biotechnol J 3(4): 510-23.

Rombaut N, Savoire R, Thomasset B, Castello J, Van Hecke E, Lanoisellé, JL. 2015. Optimization of oil yield and oil total phenolic content during grape seed cold screw pressing. I. Crops Prod. 63: 26-33.

Ross TJ. 2016. Fuzzy logic with engineering applications, 4th ed. Wiley.

Sánchez RJ, Fernández MB, Nolasco SM. 2018a. Hexane-free green solvent extraction of canola oil from microwave-pretreated seeds and of antioxidant-rich byproducts. Eur J Lipid Sci Tech 120(9): 1800209.

Sánchez R, Fernández M, Nolasco S. 2018b. Artificial neural network model for the kinetics of canola oil extraction for different seed samples and pretreatments. J Food Proc Eng 41(1): e12608.

Sánchez RJ, Fernández MB, Nolasco SM. 2019a. Canola oil with high antioxidant content obtained by combining emerging technologies: microwave, ultrasound, and a green solvent. Eur J Lipid Sci Tech 121(11): 1900152.

Sánchez RJ, Fernández MB, Nolasco SM. 2019b. Ethanol extraction of canola oil: Kinetics and effects of type of solvent and microwave-pretreatment. $O C L$ 26: 27.

Tarng Y, Yang W, Juang S. 2000. The use of fuzzy logic in the Taguchi method for the optimisation of the submerged arc welding process. Int J Adv Manuf Tech 16(9): 688-94.

Tzeng YF, Chen FC. 2007. Multi-objective optimisation of highspeed electrical discharge machining process using a Taguchi fuzzy-based approach. Mat Des 28(4): 1159-1168.

Zhou J, Wu D, Guo D. 2010. Optimization of the production of thiocarbohydrazide using the Taguchi method. J Chem Technol Biot 85(10): 1402-6.

Cite this article as: Sánchez RJ, Blas MJ, Fernández MB, Nolasco SM. 2021. Applying a Taguchi-based fuzzy logic approach to optimize hydrothermal pretreatment of canola seeds using multi-response performance index. OCL 28: 8 . 